\title{
A Novel Technique Using Proline Mesh for Simultaneous Excision and Soft Tissue Suspension in the Management of Craniofacial Neurofibromatosis Type 1
}

\author{
MOHAMED AHMED AMIN SALEH, M.D., M.R.C.S. (Eng.) \\ The Department of Plastic, Reconstruction, Maxillofacial Surgeries and Burn Management, Faculty of Medicine, \\ Ain Shams University, Cairo, Egypt
}

\begin{abstract}
Neurofibromatosis type 1 (NF-1) is an autosomal dominant disease that result in vast tumor formation. Craniofacial Neurofibromatosis is rare condition and it commonly affects the orbitotemporal midface, nose, upper lip, cheek and neck with a profound impact on the overall aesthetic outcomes in these patients. Surgical interventions is the gold standard treatment of neurofibroma. It is always complex and challenging due to the variability of the number, site, size, progress and recurrence are unpredictable. The aim of this study to present our novel technique using proline mesh for simultaneous excision and tissue suspension. It is a retrospective study reviewed 17 patients with craniofacial NF-1. Patients with intracranial extension and needed neurosurgical intervention were excluded. Objective and subjective analysis was done using the Mimics software and the need for additional surgery "NAS" score scale. Results shown that using the proline mesh to suspend the tissue hand on hand with NF1 tumor excision is of utmost importance, showing reliable long term satisfactory aesthetic outcome.
\end{abstract}

Key Words: Neurofibromatosis type 1 - Facial subunits Tissue suspension - Maxillary and mandibular deformities - Proline mesh - Orbitotemporal region-Hemifacial region-Vectors of pull.

\section{INTRODUCTION}

Neurofibromatosis type 1 (NF-1) is an autosomal dominant disease, with a single gene alteration, resulting in vast tumor formation [1]. Its cutaneous presentation makes it one of the most common visible inherited diseases [2], but also greatly affect the underlying facial skeleton [3-6].

Head and neck Neurofibromatosis is rare and accounts for 3-7\% of all neurofibromatosis cases [7]. It most commonly affects the orbitotemporal region [8], and [9] described entire classification system for this region. The midface, nose, upper lip, cheek and neck is another area of the face commonly affected in craniofacial neurofibroma- tosis with a profound impact on the overall aesthetic outcomes in these patients [10,11].

There is great variation in the clinical presentation between patients, and the resultant facial disfigurement not only functionally affect the patient but also the aesthetics of the face which downgrade the psychosocial condition, and quality of life [12].

Surgical interventions is the gold standard treatment of neurofibroma [13]. It is well-established that their no single surgical technique that allows plastic surgeons to manage the full spectrum of manifestations of craniofacial NF-1 [14-21]. The surgical management is always complex and challenging due to the variability of the number, site, size, progress and recurrence are unpredictable 13. Facial disfigurement occurs due to two mechanisms: (1) Primarily by direct infiltration of the tumor (2) Secondary by the gross deformation caused by downward traction on the skin and adjacent soft tissue.

Thus, the purpose of this study to present our novel technique using proline mesh for simultaneous excision (soft tissue, boney skeleton) and suspension of the skin and soft tissue in the management of craniofacial neurofibromatosis.

\section{PATIENTS AND METHODS}

It is a retrospective study reviewed 17 patients with craniofacial NF-1, at El Demerdash Ain Shams University Hospital between April 2015 and September 2019. All patients were operated on by a single surgeon. Only patients diagnosed as NF-1 by histopathological examination were included in the study. Only patients with followed-up data 
for at least 3 months were included. Patients with intracranial extension and needed neurosurgical intervention were excluded. Patients demographic, history, physical and clinical examination, clinical photographs and surgical procedures (number and type) and complications were collected. All patients or their parents signed an informed consent to be included in the study.

\section{Decision making and surgical goals:}

Decisions about surgical plane were individualized according to each patient specific complaint. Indication for surgical intervention was based on priority of correction of functional deficit, (e.g., exposure keratitis, visual impairment, neurological pain, difficulty in mastication, sleep apnea due to breathing difficulties, and secondarily to improve the of craniofacial deformities special in school age children which affect their emotional and social interaction.

The patient age, functional deficit, tumor size, location, recurrence, skin redundancy and previous scars all are factors which is considered. Patients or their parents were counseled and clearly discussed the nature of the diseases, limitations of surgical outcomes, recurrence and possible complications. Involvement of other specialties when needed is of utmost importance e.g.: ophthalmological, ear nose and throat, psychiatry and orthodontists according to each patient clinical condition.

\section{Preoperative marking and photography:}

Preoperative and postoperative standardized facial photographs (frontal, oblique, and lateral views) obtained at least 3, 6 and 12 months. Marking was based on the: Clinical examination, site, size of the tumor, surgical plane to achieve symmetry, least scaring and morbidity, wide exposure, the need to reconstruct the facial aesthetic units and structures, reconstruction of anatomical regions e.g.: nasolabial fold, nasofacial grove and oral commisure $[22,23]$.

\section{Surgical details:}

All surgeries were performed under general anesthesia. Broad spectrum antibiotic was administered and infiltration with adrenaline: Normal saline in concentration (1:200000) to reduce bleeding. Incisions done along the preoperative marking. An electro cautery and bipolar coagulation were used during resection. Identifying the facial nerve branches using nerve stimulator was done unless they were previously injured or destroyed by the tumor.
The surgical technique used were tailored to each patient clinical condition.

\section{Different modalities were used:}

1- Different surgical incisions adopted: Coronal, semi coronal, subcilliary, intraoral, preauricular, rhytidectomy, submandibular and previous scars were used.

2- Excision according to the site of the tumor i.e. temporal, orbital, midface, neck, en bloc translational excisions according the facial aesthetic unit principle.

3- Preservation of important structures i.e.: levator palpebrae superioris muscle, medial and lateral canthi, facial nerve and its branches, parotid duct, parotid and submandibular gland.

4- Boney skeleton corrective osteotomies, shaving, debulking and bone graft.

5- Tissue suspensions with different vectors needed for: Upper face including the eyebrow, lower eye lid canthoplasty, mid face including: SMAS layer, malar pad fat, oral commissure, nasolabial fold and alla of the nose, lower face including the neck (platysma muscle layer).

6- Titanium mesh is used to reconstruct the temporal hollowness resulted from excision of the orbitotemporal lesions, it was also used for reconstruction of the nasolabial fold and anchor the alla of the nose.

7- Excess skin was excised according to the degree of redundancy.

Tissue suspension was done in all our patients using proline mesh. The mesh was tailored according to the region suspended. The mesh was designed in the form of strips. The strips width were designed as much broad as possible to create as much as tissue contact and fibrosis to insure adequate tissue reaction and suspension. The length of the strips were tailored after traction over the anchored strip according to the area needed. The steps of suspension was as follows:

- Cutting the proline mesh into strips.

- Anchoring the caudal part with two rows of interrupted proline sutures (round 3/0 and 4/0). The first row fixed to the deed tissue i.e. submuscular aponeurotic system or lateral canthus. The second raw fixed to the superficial tissue layers i.e. the subcutaneous tissue and the dermis.

- Tension is applied over the proline mesh strips and the cranial sutures applied with extra tension in the pre-planned vector of pull (Figs. 6,7). The 
caudal stitches are anchored to the periostium of the orbital, body of zygoma and zygomatic arch according to the suspension done.

\section{Post-operative care:}

Light compression dressing were applied to all patients. Patients laid down in semi sitting position. Cold fomentation for the first 48 hours followed by hot fomentation up to two weeks. Intravenous antibiotics administered till the drain is removed, shifting to oral route for one week. Drains removed when it's minimal amount (less than 30cc). Dressing is done at the $5^{\text {th }}$ to $7^{\text {th }}$ postoperative day. Nonabsorbable stitches were removed from post-operative days 7 to 10. All patients instructed to follow-up in the outpatient clinic at two weeks, one, three, six and twelve months afterward. Patients was informed about possible progress, malignant potential and recurrence which might entail surgical intervention.

\section{Clinical assessment:}

In this study objective and subjective analysis was done. Mimics software provide accurate analysis, simulation and modeling based on the DICOM files of the computed tomographic (CT) images and cost-efficient $[\mathbf{2 4 , 2 5 , 2 6 ]}$. The pre and postoperative CT scans DICOM files were retrieved and the soft tissue model for the midface was reconstructed by Mimics10 software (Materialise NV, Inc, Leuven, Belgium). Thus, Mimics software was applied to evaluate the pre- and postoperative symmetry of the midface, through which we could calculate the symmetry improvement (Table 4 and Diagram 5).

Subjective analysis is carried by 3 plastic surgeons who did not participate in the surgery. Standardized facial photographs were used to analyze the clinical results. Based on the need for additional surgery "NAS" score scale 27 results was categorized: Category I (3 points), no refinements or additional surgical revisions advisable; for Category II (2 points), soft tissue contouring revisions were advisable; Category III (1 point) require a considerable number of revision surgeries (not as the original procedure); and in Category IV (0 points), a major procedure is advisable, duplicating or exceeding the previous one (Table 3 and Diagram 4).

\section{RESULTS}

Patients included in the study age ranged (941 years), with mean age 23.47 ( \pm 9.97$)$ years. Male to female ratio was analyzed with equal ratio in orbitotemporal, 3: 5 in hemifacial and 1:4 in orbitotemporal lesions (Table 1 and Diagram 1).
Table (1): Patients' characteristics.

\begin{tabular}{|c|c|c|c|c|c|c|}
\hline \# & Sex & $\begin{array}{l}\text { Age/ } \\
\text { year }\end{array}$ & $\begin{array}{l}\text { Region } \\
\text { affected }\end{array}$ & $\begin{array}{l}\text { No. surgical } \\
\text { intervention }\end{array}$ & $\begin{array}{l}\text { Hospital } \\
\text { stay/day }\end{array}$ & $\begin{array}{c}\text { Follow-up/ } \\
\text { month }\end{array}$ \\
\hline 1 & F & 16 & OT & 2 & 3 & 13 \\
\hline 2 & M & 21 & OT & 1 & 3 & 12 \\
\hline 3 & M & 10 & $\begin{array}{l}\text { OT, } \\
\text { Hemifacial }\end{array}$ & 0 & 5 & 15 \\
\hline 4 & F & 25 & $\begin{array}{l}\text { OT, } \\
\text { Hemifacial }\end{array}$ & 3 & 5 & 24 \\
\hline 5 & F & 18 & Hemifacial & 3 & 2 & 12 \\
\hline 6 & F & 9 & $\begin{array}{l}\text { OT, } \\
\text { Hemifacial }\end{array}$ & 0 & 4 & 15 \\
\hline 7 & M & 22 & Hemifacial & 2 & 3 & 18 \\
\hline 8 & M & 28 & Hemifacial & 2 & 4 & 13 \\
\hline 9 & M & 31 & OT & 3 & 3 & 27 \\
\hline 10 & $\mathrm{~F}$ & 14 & Hemifacial & 1 & 5 & 16 \\
\hline 11 & $\mathrm{~F}$ & 35 & $\begin{array}{l}\text { OT, } \\
\text { Hemifacial }\end{array}$ & 2 & 5 & 12 \\
\hline 12 & $\mathrm{~F}$ & 41 & Hemifacial & 4 & 6 & 14 \\
\hline 13 & $\mathrm{~F}$ & 13 & Hemifacial & 1 & 4 & 12 \\
\hline 14 & $\mathrm{~F}$ & 39 & Hemifacial & 2 & 4 & 17 \\
\hline 15 & $\mathrm{~F}$ & 33 & OT & 2 & 3 & 19 \\
\hline 16 & $\mathrm{M}$ & 17 & Hemifacial & 3 & 4 & 14 \\
\hline 17 & $\mathrm{~F}$ & 27 & OT & 1 & 2 & 12 \\
\hline
\end{tabular}

OT: Orbitotemporal.

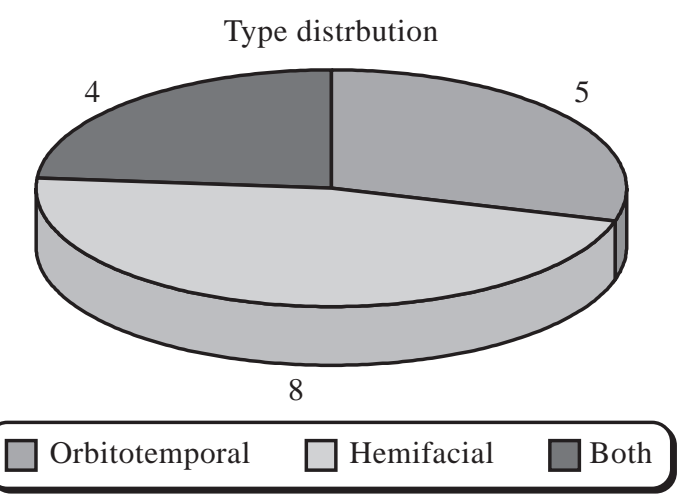

Diagram (1): Patients distribution according to the site of lesion.

The mean follow-up time was $15.59( \pm 4.36)$ months with maximum time in patients having orbitotemporal lesions $16.60( \pm 6.50)$ months and minimum in patients having hemifacial lesions $16.60( \pm 6.50)$ months. The mean hospital stay 3.82 $( \pm 1.13)$ days. The longest hospital stay $4.75( \pm 0.50)$ days in patients having both orbitotemporal and hemifacial lesions and shortest $2.80( \pm 0.45)$ days in patients having orbitotemporal lesions. The mean number of previous surgical procedures was $1.88( \pm 1.11)$ more frequent in hemifacial lesions $2.25( \pm 1.04)$, and least in patients having both orbitotemporal and hemifacial lesions (Table 2 and Diagrams 2,3). 
Table (2): Patients distribution.

\begin{tabular}{|c|c|c|c|c|c|c|c|c|c|c|}
\hline \multirow{2}{*}{ NF-1 } & \multirow{2}{*}{ Patient no. } & \multirow{2}{*}{ Male/Female } & \multicolumn{2}{|c|}{ Age } & \multicolumn{2}{|c|}{ Follow-up } & \multicolumn{2}{|c|}{ Hospital stay } & \multicolumn{2}{|c|}{$\begin{array}{l}\text { No. of surgical } \\
\text { intervention }\end{array}$} \\
\hline & & & Mean & SD & Mean & SD & Mean & SD & Mean & SD \\
\hline Orbitotemporal & 5 & $1 / 4$ & 25.60 & 7.06 & 16.60 & 6.50 & 2.80 & 0.45 & 1.80 & 0.84 \\
\hline Hemifacial & 8 & $3 / 5$ & 22.25 & 9.19 & 14.50 & 2.27 & 4.00 & 1.20 & 2.25 & 1.04 \\
\hline Both & 4 & $2 / 2$ & 23.25 & 15.97 & 16.50 & 5.20 & 4.75 & 0.50 & 1.25 & 1.50 \\
\hline Total & 17 & $6 / 11$ & 23.47 & 9.97 & 15.59 & 4.36 & 3.82 & 1.13 & 1.88 & 1.11 \\
\hline
\end{tabular}

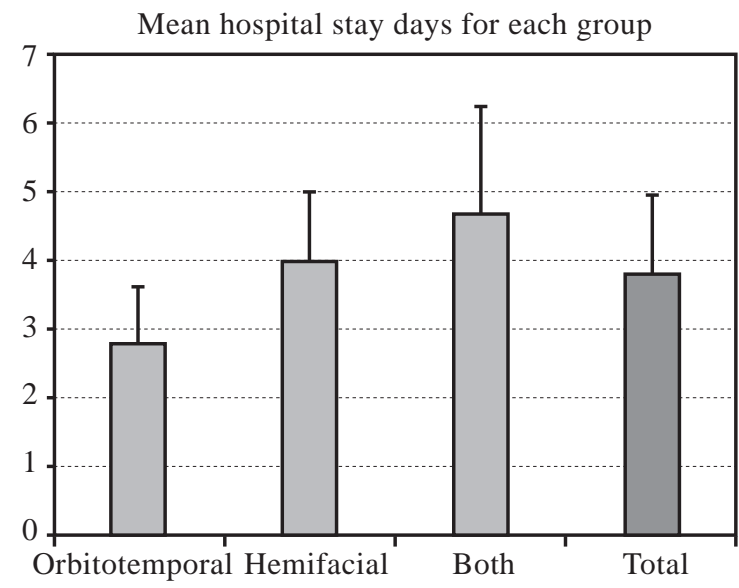

Diagram (2): Relation between the site of lesion and mean duration of the hospital stay.

All patients were evaluated postoperatively using the subjective NAS score and the objective symmetry assessment using mimics software. Clinical assessment at 1 and 3 months and at the last follow-up was done in the outpatient clinic as regard functional and aesthetic outcome. CT scan

Table (3): NAS score; need for additional surgery score.

\begin{tabular}{|c|c|c|c|c|c|}
\hline \multirow{2}{*}{ \# } & \multicolumn{3}{|c|}{ NAS score scale } & \multirow{2}{*}{$\begin{array}{l}\text { Mean score for } \\
\text { each patient }\end{array}$} & \multirow{2}{*}{ SD } \\
\hline & A & B & C & & \\
\hline 1 & 1 & 2 & 1 & 1.33 & 0.58 \\
\hline 2 & 2 & 2 & 1 & 1.67 & 0.58 \\
\hline 3 & 3 & 3 & 3 & 3.00 & 0.00 \\
\hline 4 & 3 & 2 & 3 & 2.67 & 0.58 \\
\hline 5 & 2 & 2 & 2 & 2.00 & 0.00 \\
\hline 6 & 3 & 2 & 2 & 2.33 & 0.58 \\
\hline 7 & 1 & 1 & 2 & 1.33 & 0.58 \\
\hline 8 & 2 & 2 & 2 & 2.00 & 0.00 \\
\hline 9 & 2 & 3 & 2 & 2.33 & 0.58 \\
\hline 10 & 3 & 2 & 3 & 2.67 & 0.58 \\
\hline 11 & 2 & 1 & 2 & 1.67 & 0.58 \\
\hline 12 & 2 & 2 & 2 & 2.00 & 0.00 \\
\hline 13 & 1 & 1 & 2 & 1.33 & 0.58 \\
\hline 14 & 2 & 2 & 3 & 2.33 & 0.58 \\
\hline 15 & 3 & 2 & 3 & 2.67 & 0.58 \\
\hline 16 & 2 & 2 & 1 & 1.67 & 0.58 \\
\hline 17 & 3 & 2 & 2 & 2.33 & 0.58 \\
\hline $\begin{array}{l}\text { Mean score for } \\
\text { each Doctor }\end{array}$ & 2.18 & 1.94 & 2.12 & & \\
\hline $\begin{array}{l}\text { Total score } \\
\text { average }\end{array}$ & & & & 2.08 & 0.12 \\
\hline
\end{tabular}

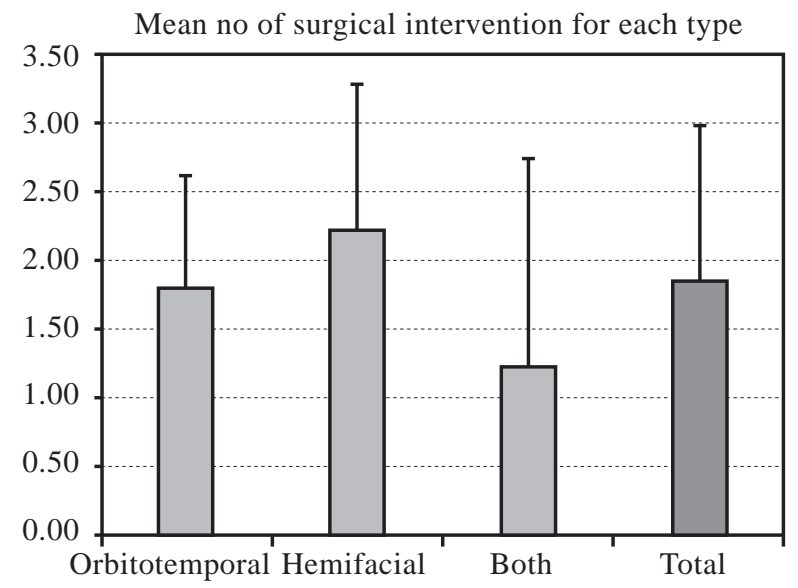

Diagram (3): Relation between the site of lesion and mean number of previous surgical interventions.

and Photographs (minimum at 3 months) was examined. The average subjective NAS score was $2.08( \pm 0.12)$, there was three patients complaint of unsatisfactory results (one orbitotemporal and two hemifacial lesions) with an average 1.33 $( \pm 0.58)$ (Table 3 and Diagram 4).

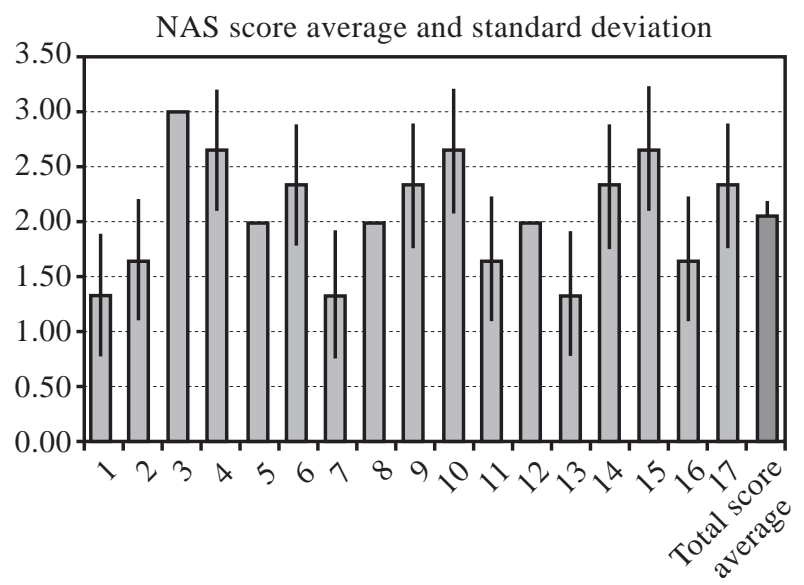

Diagram (4): Mean NAS score in all patients.

The relation between the site of lesion and the NAS score was calculated showing the mean need for additional surgery was highest (2.4175) among patients with both orbitotemporal and hemifacial lesion and lowest (2.066) among patients with hemifacial lesions (Diagram 5). 


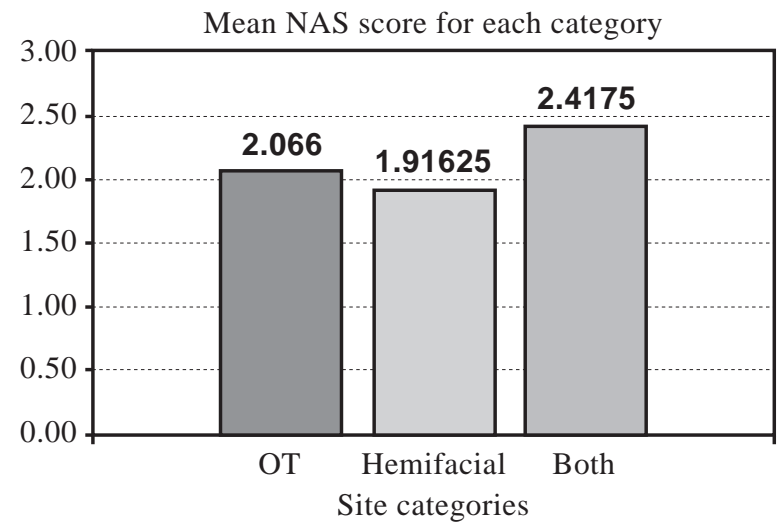

Diagram (5): Relation between the site of lesion and the NAS score.
All patients underwent the postoperative CT, symmetry improvement was observed in all patients, with an average $8.90 \%( \pm) 4.89 \%$, and only patient number 8 was shown unsatisfactory result $-3.00 \%$ (Table 4 and Diagram 6).

Showing the relation between the pre and postoperative symmetry improvement in different site of lesions were calculated showing the mean percentage of improvement was highest $(9.51 \%)$ among patients with hemifacial lesions and lowest (7.9\%) among patients with both orbitotemporal and hemifacial lesions (Diagram 7).

Table (4): Symmetry improvement in all patients evaluated by mimic's soft wear.

\begin{tabular}{|c|c|c|c|c|c|c|c|}
\hline \multirow{2}{*}{$\begin{array}{l}\text { Patient } \\
\text { No. }\end{array}$} & \multicolumn{2}{|c|}{$\begin{array}{l}\text { Pre-operative } \\
\text { volume (ml) }\end{array}$} & \multicolumn{2}{|c|}{$\begin{array}{l}\text { Post-operative } \\
\text { volume }(\mathrm{ml})\end{array}$} & \multirow{2}{*}{$\begin{array}{l}\text { Pre-operative } \\
\text { symmetry \% } \\
\text { B1/A1 }\end{array}$} & \multirow{2}{*}{$\begin{array}{l}\text { Post-operative } \\
\text { symmetry } \% \\
\text { B2/A2 }\end{array}$} & \multirow{2}{*}{$\begin{array}{c}\text { Symmetry } \\
\text { improvement } \\
\%\end{array}$} \\
\hline & $\begin{array}{l}\text { Affected } \\
\text { side A1 }\end{array}$ & $\begin{array}{l}\text { Unaffected } \\
\text { side B } 1\end{array}$ & $\begin{array}{l}\text { Affected } \\
\text { side A2 }\end{array}$ & $\begin{array}{l}\text { Unaffected } \\
\text { B2 }\end{array}$ & & & \\
\hline 1 & 440231 & 350542 & 418365 & 360523 & $79.63 \%$ & $86.17 \%$ & $6.55 \%$ \\
\hline 2 & 398122 & 320463 & 360147 & 318254 & $80.49 \%$ & $88.37 \%$ & $7.87 \%$ \\
\hline 3 & 658789 & 510254 & 590547 & 523625 & $77.45 \%$ & $88.67 \%$ & $11.21 \%$ \\
\hline 4 & 625478 & 498563 & 587453 & 480658 & $79.71 \%$ & $81.82 \%$ & $2.11 \%$ \\
\hline 5 & 568245 & 498563 & 498523 & 486589 & $87.74 \%$ & $97.61 \%$ & $9.87 \%$ \\
\hline 6 & 658963 & 510245 & 578963 & 520365 & $77.43 \%$ & $89.88 \%$ & $12.45 \%$ \\
\hline 7 & 596321 & 504589 & 558963 & 512546 & $84.62 \%$ & $91.70 \%$ & $7.08 \%$ \\
\hline 8 & 521483 & 486589 & 465236 & 420145 & $93.31 \%$ & $90.31 \%$ & $-3.00 \%$ \\
\hline 9 & 482635 & 378542 & 430158 & 368458 & $78.43 \%$ & $85.66 \%$ & $7.22 \%$ \\
\hline 10 & 587325 & 481523 & 511547 & 465896 & $81.99 \%$ & $91.08 \%$ & $9.09 \%$ \\
\hline 11 & 632987 & 500254 & 585632 & 498652 & $79.03 \%$ & $85.15 \%$ & $6.12 \%$ \\
\hline 12 & 605412 & 536547 & 520369 & 502547 & $88.63 \%$ & $96.58 \%$ & $7.95 \%$ \\
\hline 13 & 498652 & 410985 & 412583 & 408965 & $82.42 \%$ & $99.12 \%$ & $16.70 \%$ \\
\hline 14 & 545896 & 445236 & 465896 & 440256 & $81.56 \%$ & $94.50 \%$ & $12.94 \%$ \\
\hline 15 & 410258 & 305425 & 375695 & 306548 & $74.45 \%$ & $81.59 \%$ & $7.15 \%$ \\
\hline 16 & 499587 & 410258 & 415698 & 405569 & $82.12 \%$ & $97.56 \%$ & $15.44 \%$ \\
\hline \multirow[t]{3}{*}{17} & 380459 & 307895 & 345896 & 330254 & $80.93 \%$ & $95.48 \%$ & $14.55 \%$ \\
\hline & & & & & & Mean & $8.90 \%$ \\
\hline & & & & & & SD & $4.89 \%$ \\
\hline
\end{tabular}

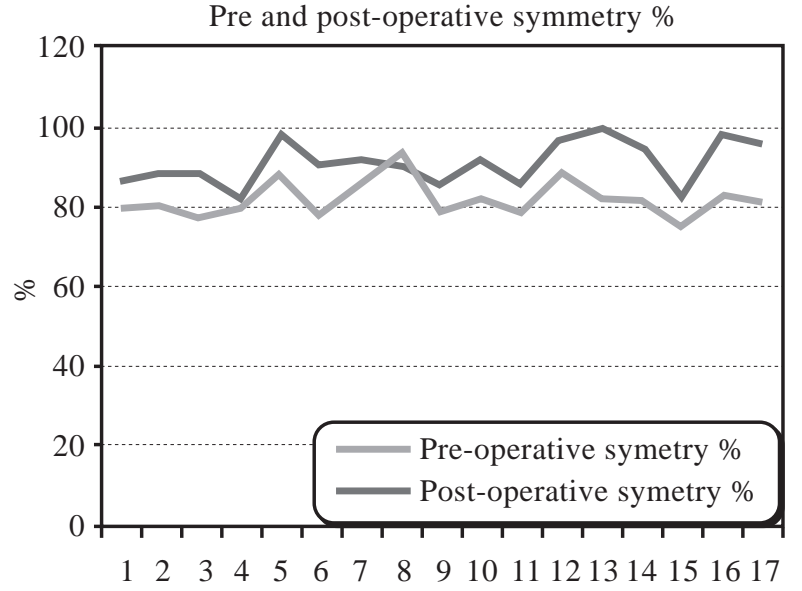

Diagram (6): Relation between the pre and post-operative symmetry improvement in all patients evaluated by mimic's soft wear.

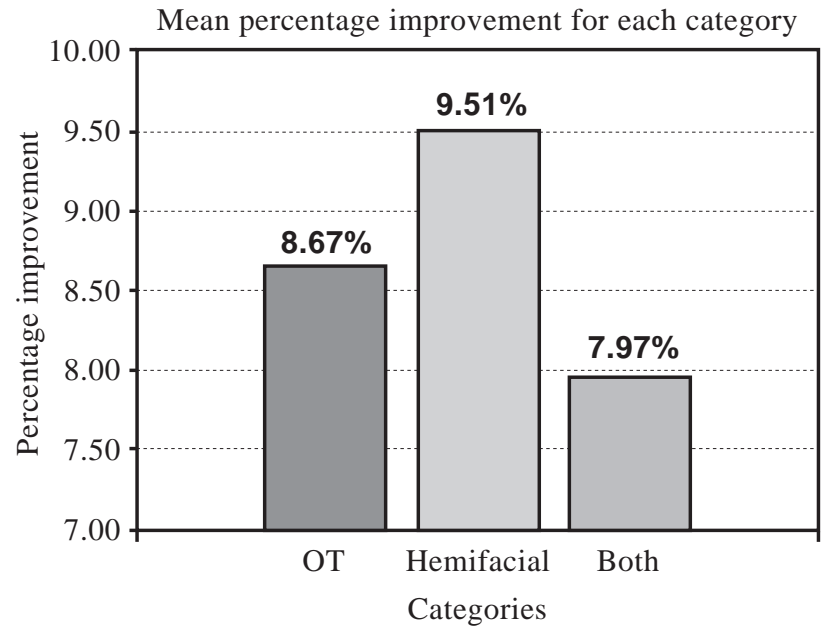

Diagram (7): Relation between the pre and post-operative symmetry improvement in different site of lesions. 
Postoperative complication were recorded and analyzed. Including hematoma, seroma, infection, delayed healing and skin flap necrosis, injury to important structures e.g. facial nerve and the need for secondary procedure.

None of the patients included in the study had iatrogenic injury to the facial nerve, parotid gland or duct, levator muscle etc. None of our patients had hematoma. One patient with hemifacial NF1 had skin flap necrosis over the mandibular region due to the presence of previous scars, managed with frequent dressing and 2ry sutures under local anesthesia. One patient had seroma in the orbitotemporal region due to blockage of the drain, which required reinsertion of another suction drain under local anesthesia. One patient developed wound infection and exposure of the proline mesh, at the oral commissure, treated with antibiotics according to the culture and sensitivity, frequent dressing, trimming the exposed part of the mesh and 2ry suture under local anesthesia.

Figs. (1-14) show some of the clinical cases. All patients still follow in the outpatient clinic.
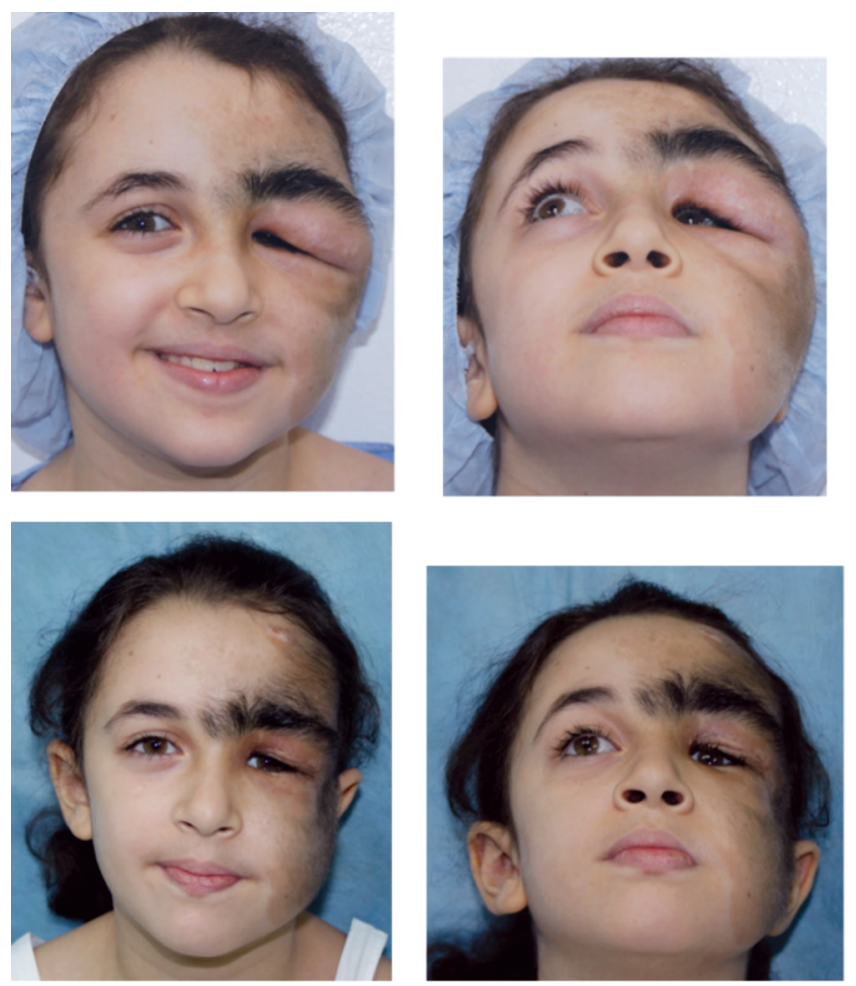
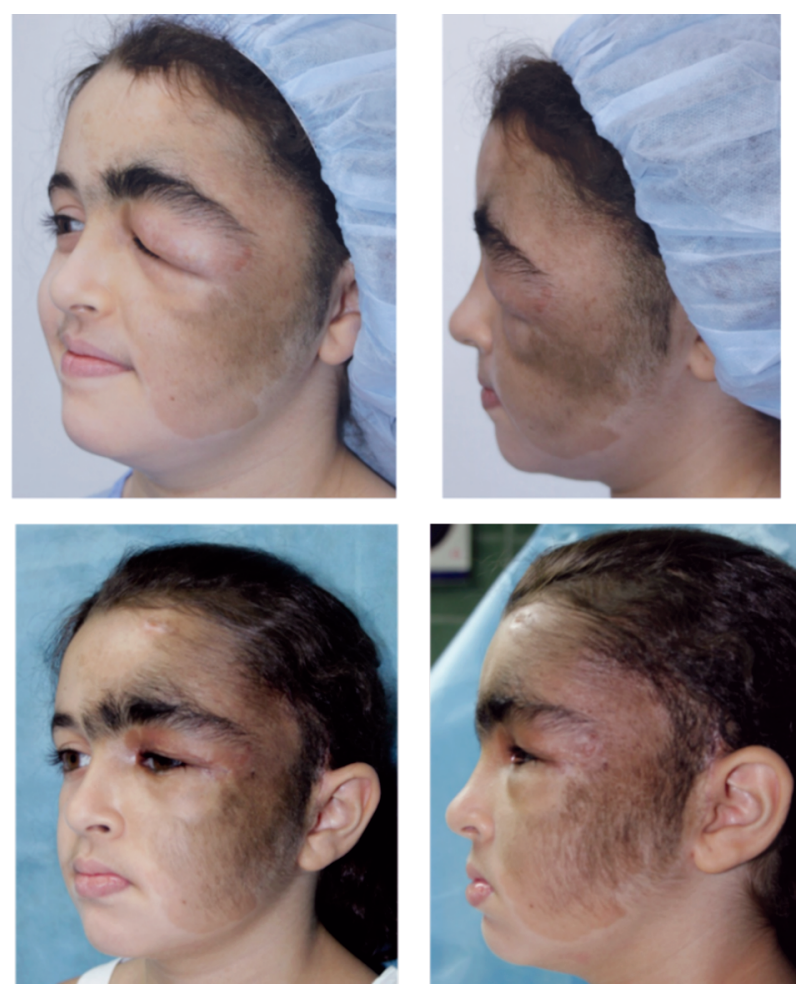

\section{Case presentation:}

Case (1): This patient is a 9 year old young girl with left orbitotemporal neurofibromatosis affecting all elements of the periorbita. The patient suffered impaired vision of the left eye. Soft tissue involvement also included the left temporal region, upper and lower eye lids and cheek. The patient's craniofacial skeleton revealed widening of the left inferior orbital rim. The patient has no family history. Single stage excision was done to de bulk most of the tumor at the temporal orbital and mid face regions, using upper, lower blepharoplasty, poral and extended preauricular incisions. le preserving the levator muscle when excising the tumor from the upper lid. Reconstruction of She has been followed for 1 year after surgery. She had seroma in the orbitotemporal region due to blockage of the drain, which required reinsertion of another suction drain under local anesthesia. As an additional procedure after surgery she had sessions of hair removal to improve symmetry of eye brows. Total hospital stay was 4 days and she followed-up for 15 month in the outpatient clinic (Figs. 1-3).

Fig. (1): 9 year old young girl with left orbitotemporal neurofibromatosis affecting all elements of the periorbita. The patient suffered impaired vision of the left eye. Soft tissue involvement also included the left temporal region, upper and lower eye lids and cheek. Pre-operative photos upper row, post-operative photos lower row, with 15 month post-operative follow-up. 

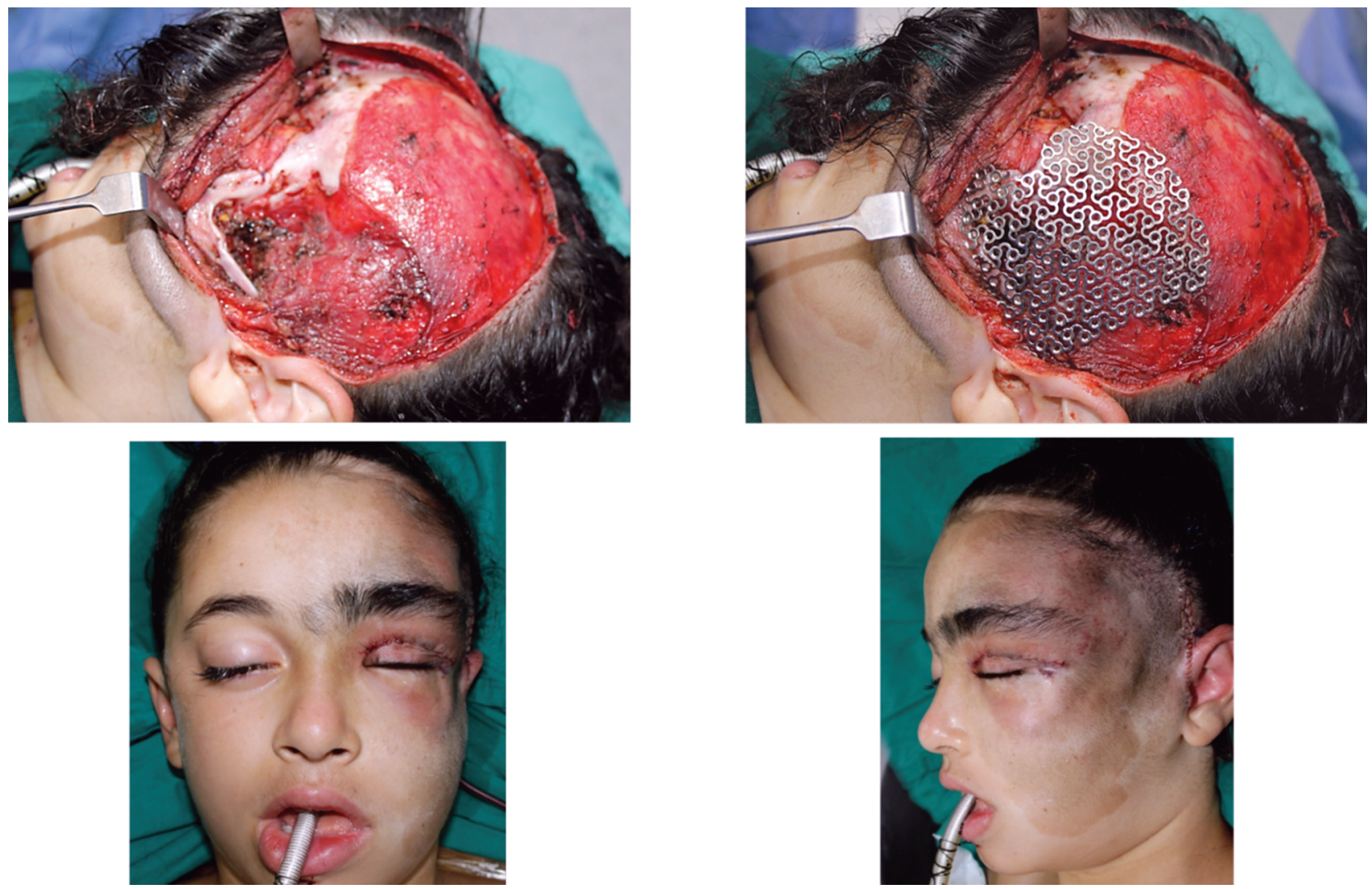

Fig. (2): Intra operative photos showing the titanium mesh used to reconstruct the temporal region, incisions used and the immediate post-operative result.
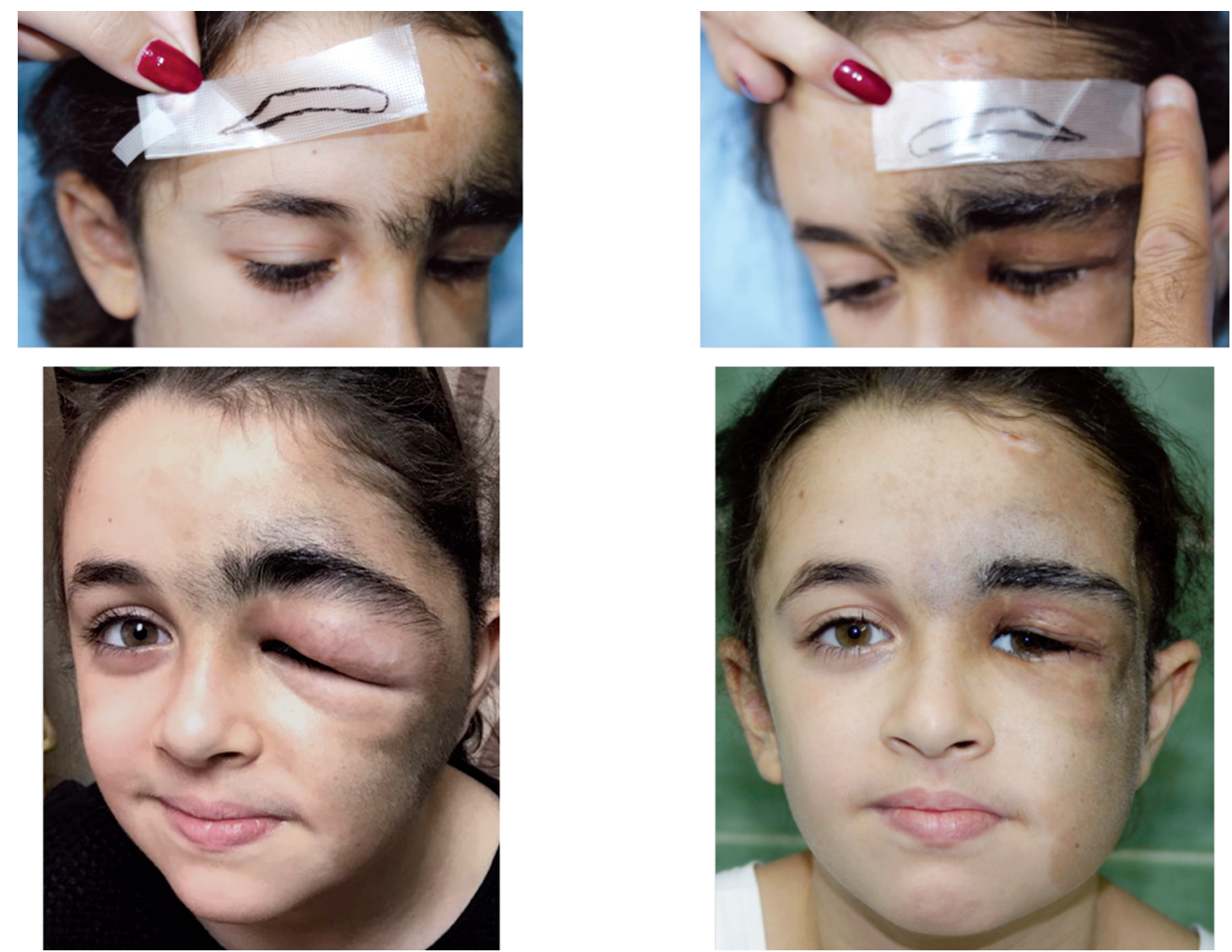

Fig. (3): Hair removal was done to the left eye brow using a template from the health side and Alexandrite laser. 
Case 2: This is a Female patient 25 years old with orbitotemporal and hemifacial involvement. She was previously operated three time before at another center. She showed recurrence of the tumor. A single stage approach for debulking most of the tumor from the temporal, orbit and preauricular incisions. Trans lesion debulking was done to the tumor over the chin. Total hospital stay was 5 days and she followed up for 24 month in the outpatient clinic (Figs. 4-7).
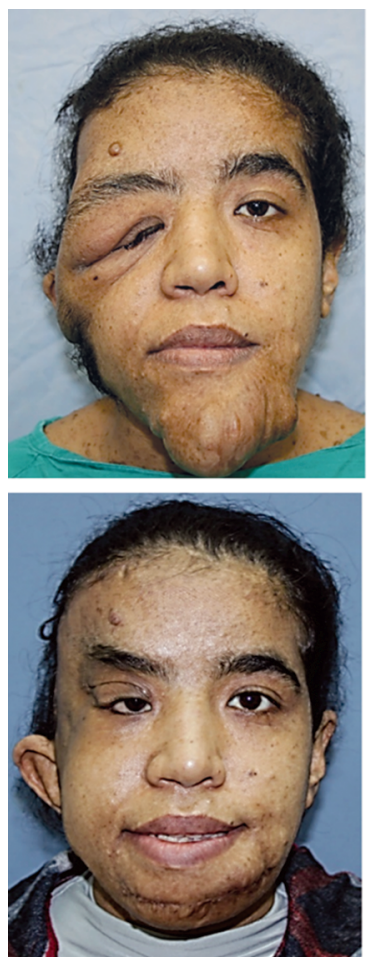
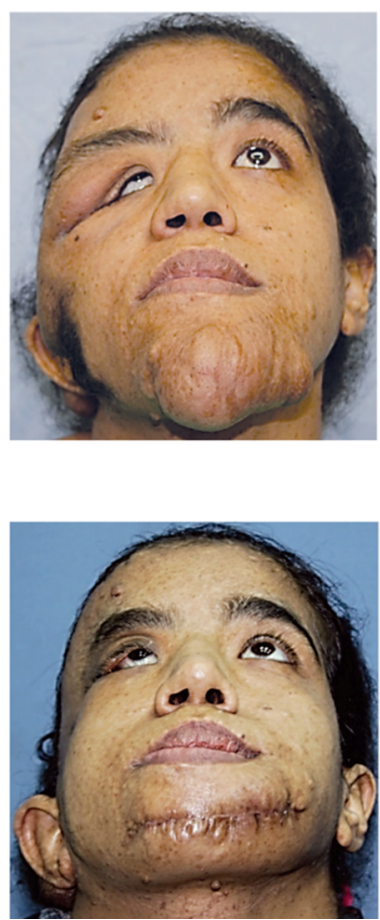
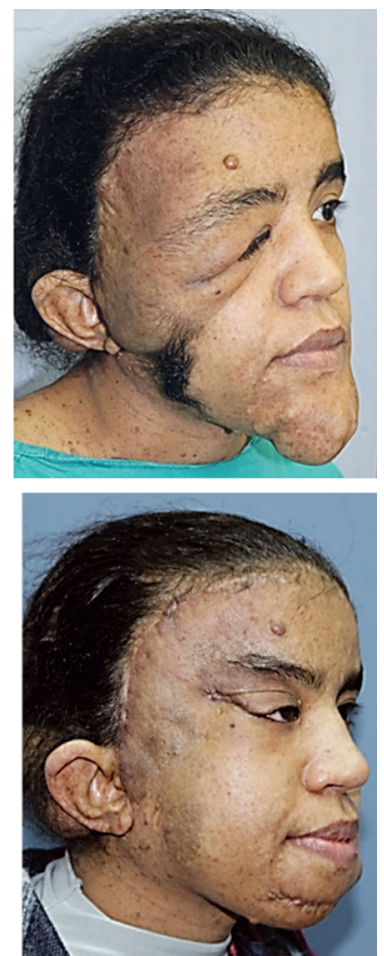

Fig. (4): Female patient 25 years old with orbitotemporal and hemifacial involvement. She was previously operated three time before at another center. She showed recurrence of the tumor. A single stage approach for debulking most of the tumor from the temporal, orbit and preauricular incisions. Trans lesion debulking was done to the tumor over the chin. Preoperative photos upper row, post-operative photos lower row, with 24 month post-operative follow-up.
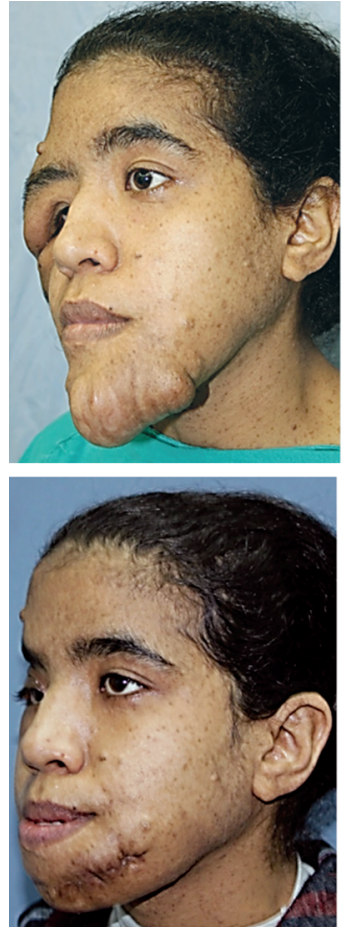
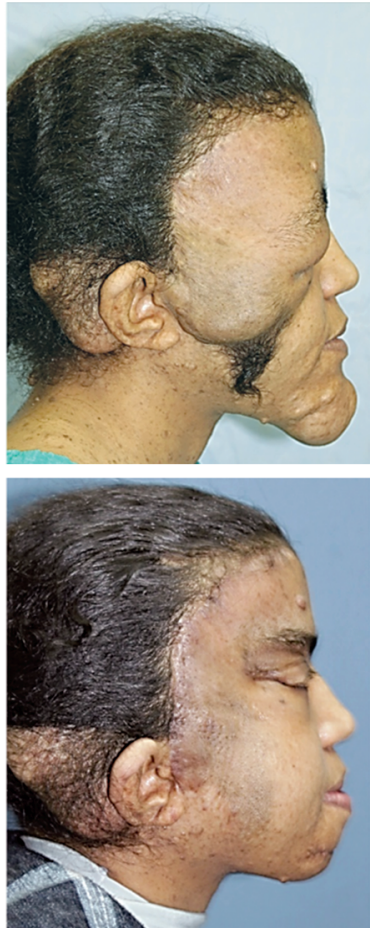
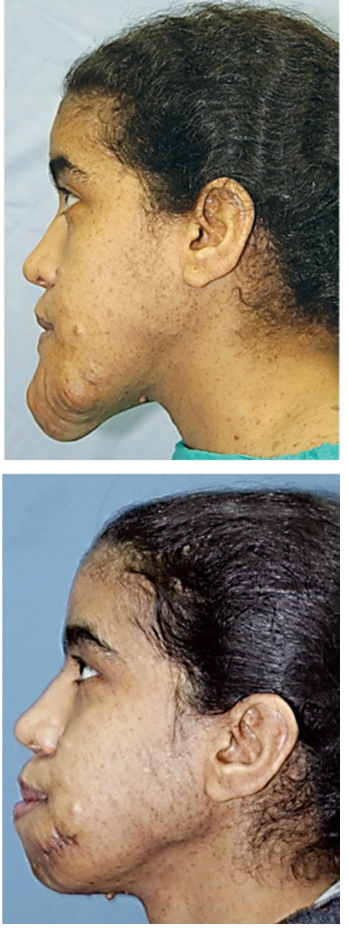

Fig. (5): Rest of the Pre-operative photos upper row, post-operative lower row. 


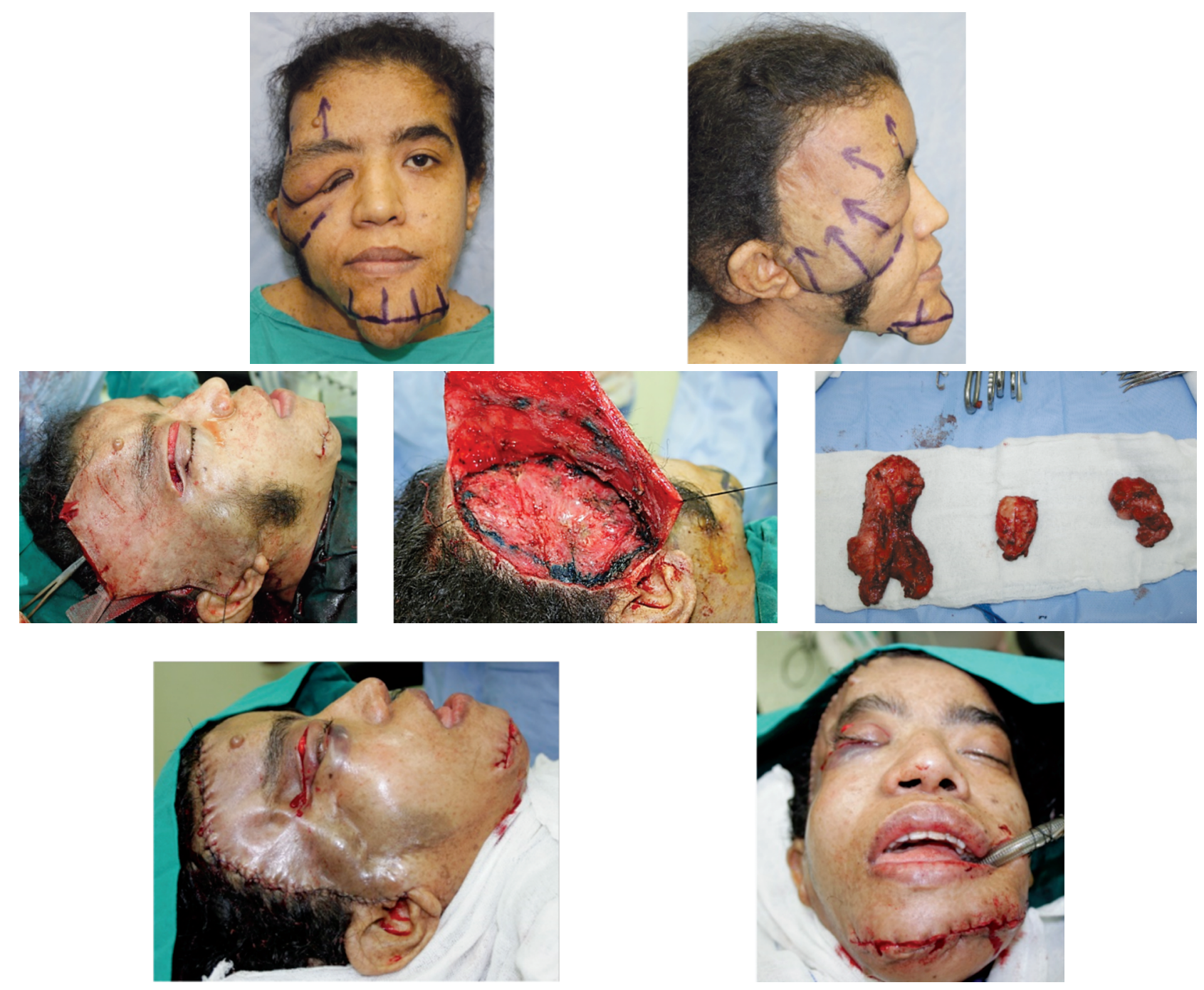

Fig. (6): Intra operative photos showing the different vectors of pull, incisions used lesion excited "marked with blue ink" and the immediate post-operative result.
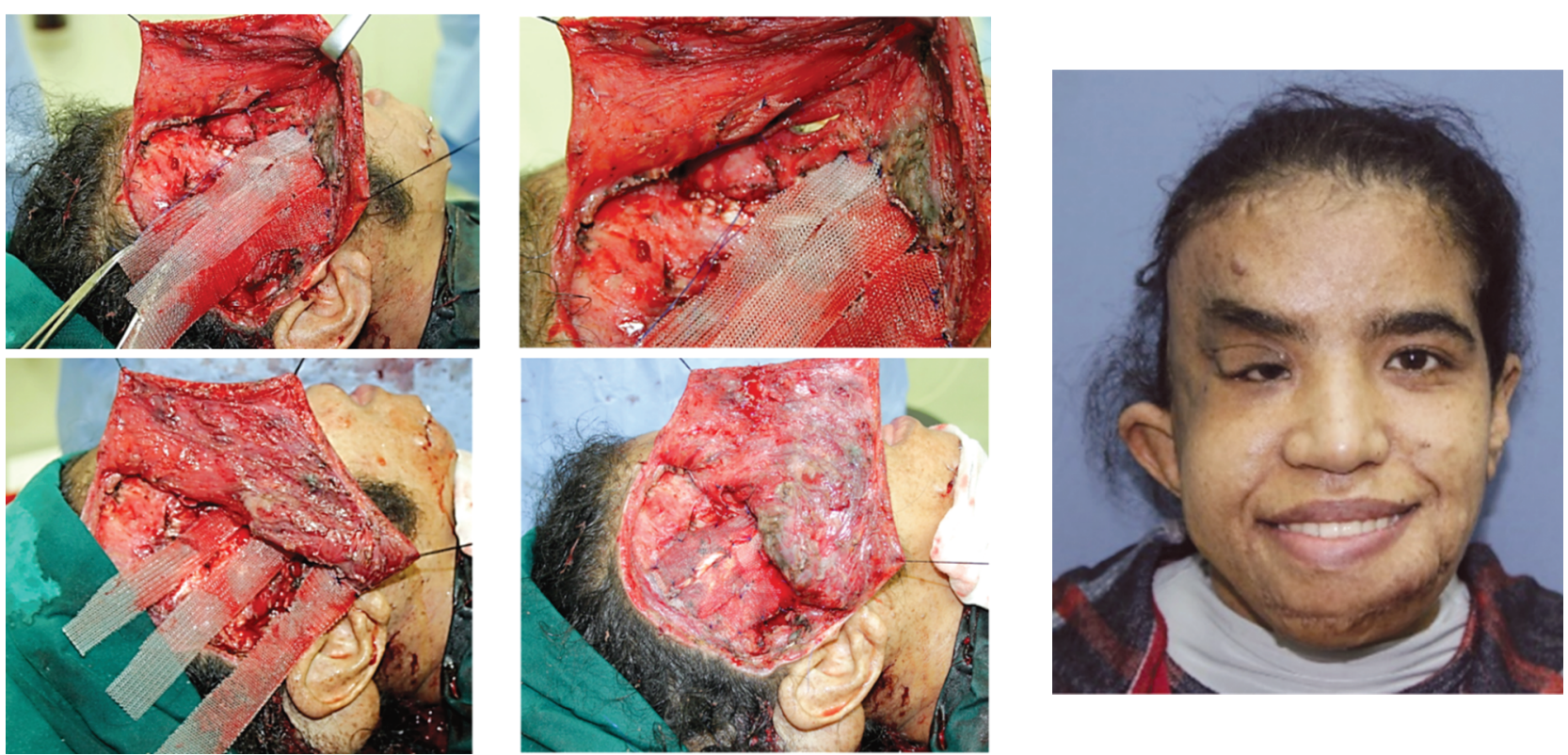

Fig. (7): Intra operative photos showing the different vectors of pull, different strips of proline mesh used and the immediate post-operative result while the patient is smiling. 
Case 3: This case is a male patient 22 years old with neurofibromatosis affecting the midface with skeletal deformity in the form of maxillary and mandibular hypertrophy. A single stage debulking of the tumor and no skeletal maxilla or mandibular osteotomies or shaving was done. The incisions used: Preauricular and submandibular incisions. He was operated twice in another center. Facial nerve was affected in previous surgeries. He developed wound infection and exposure of the proline mesh, at the oral commissure, treated with antibiotics according to the culture and sensitivity, frequent dressing, trimming the exposed part of the mesh and 2ry suture under local anesthesia. Total hospital stay was 4 days and she followed-up for 18 month in the outpatient clinic (Figs. 8-10).
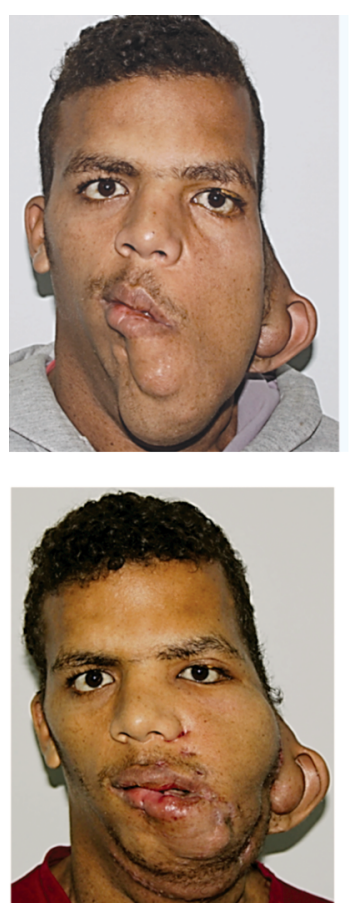
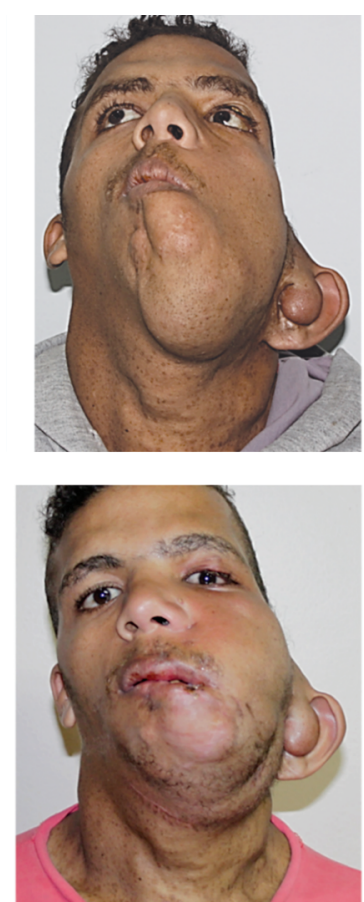
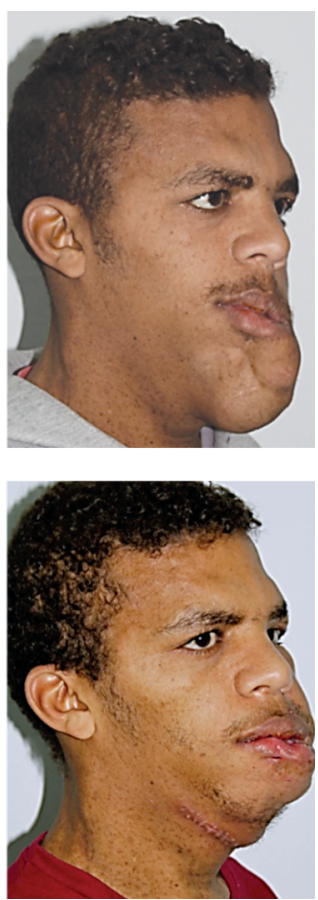

Fig. (8): Male patient 22 years old with neurofibromatosis affecting the midface with skeletal deformity in the form of maxillary and mandibular hypertrophy. A single stage debulking of the tumor and no skeletal maxilla or mandibular osteotomies or shaving was done. The incisions used: Preauricular and submandibular incisions. He was operated twice in another center. Pre-operative photos upper row, post-operative photos lower row, with 18 month post-operative follow-up.
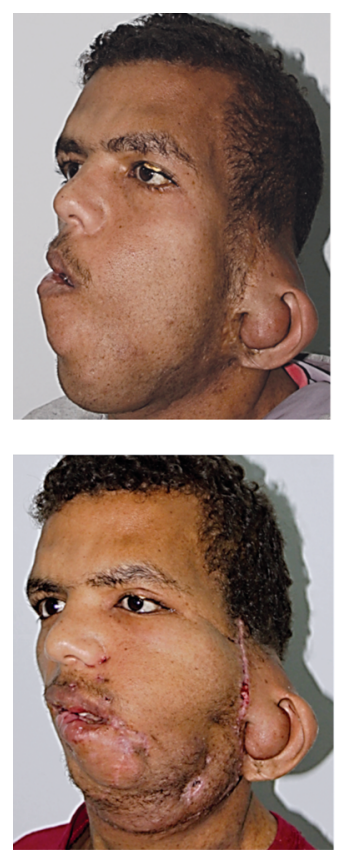
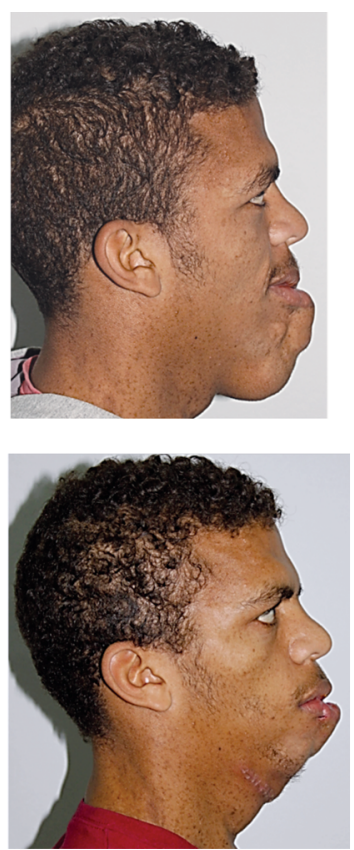
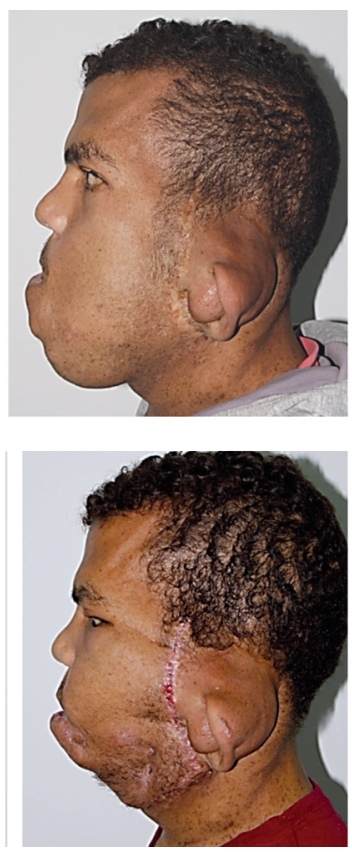

Fig (9): Rest of the Pre-operative photos upper row, post-operative photos lower row. 

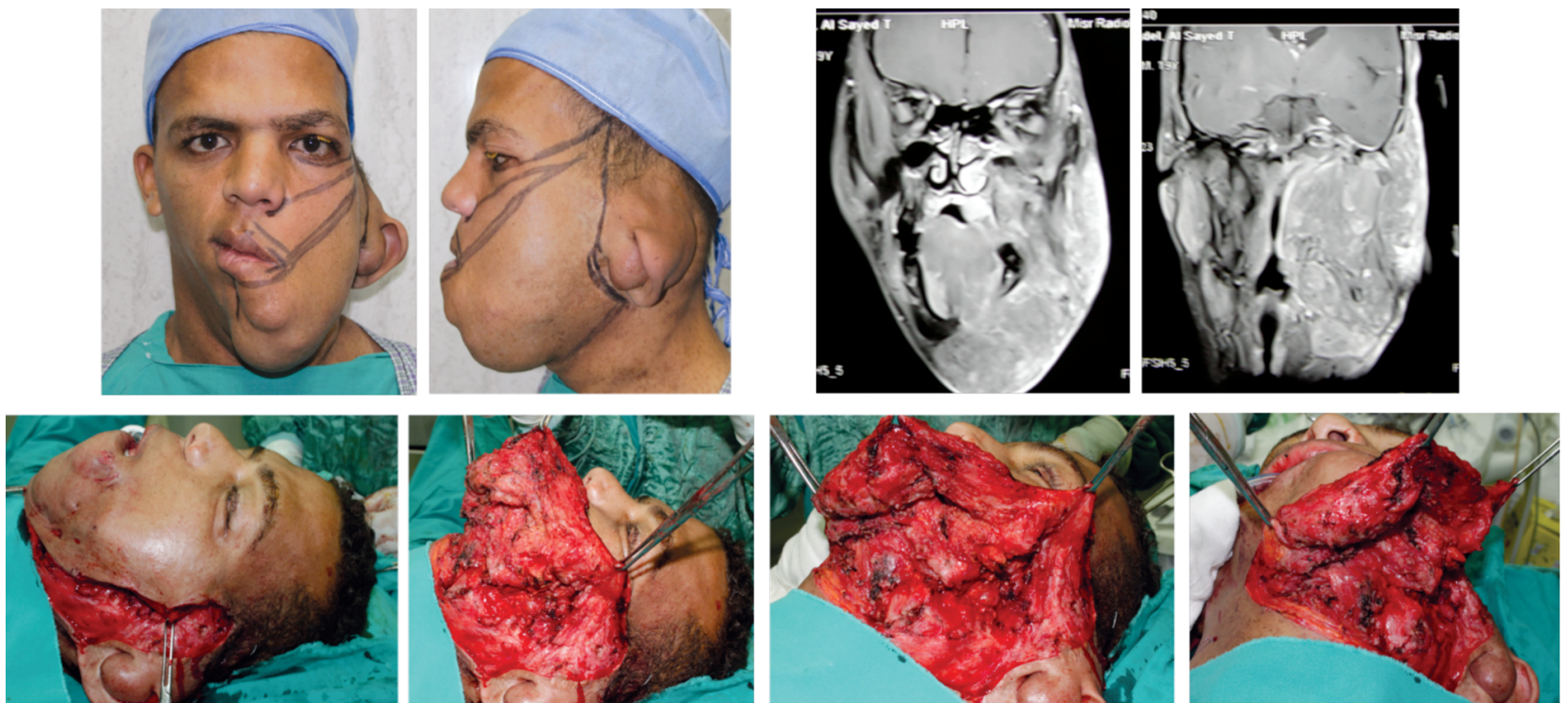

Fig. (10): Intra operative photos showing the different vectors of pull, coronal cuts of CT scan showing the huge dimension of the tumor and the incisions used to excise the lesion.

Case 4: This case is female patient 18 years old with neurofibromatosis affecting the midface with skeletal deformity in the form of maxillary hypertrophy. A single stage debulking of the tumor was and no skeletal maxilla osteotomies or shaving was done. The incisions used: At the scars of previous surgeries i.e. the nasolabial fold and side of the nose. She was operated three times in another center. The aim in this case was to restore nasal, nasolabial fold symmetry, correct the telecanthus and tumor debulking. Trans-nasal canthopexy, proline mesh was sutured to the titanium mesh which is fixed to the boney nasal buttress to restore the nasal and nasolabial fold. Wedge excision of the alla and suspension using the proline mesh, tumor debulking at the lower and upper lip. Facial nerve was not affected in previous surgeries Total hospital stay was 2 days and she followed up for 12 month in the outpatient clinic (Figs. 11-14).
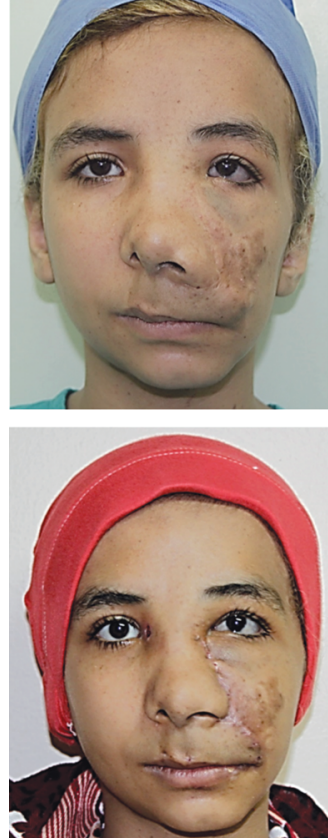
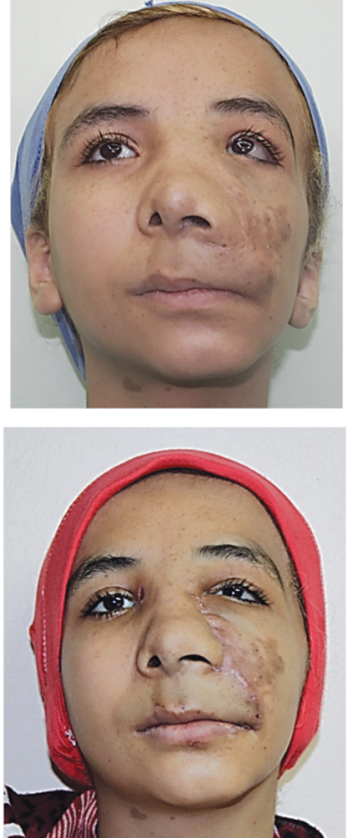
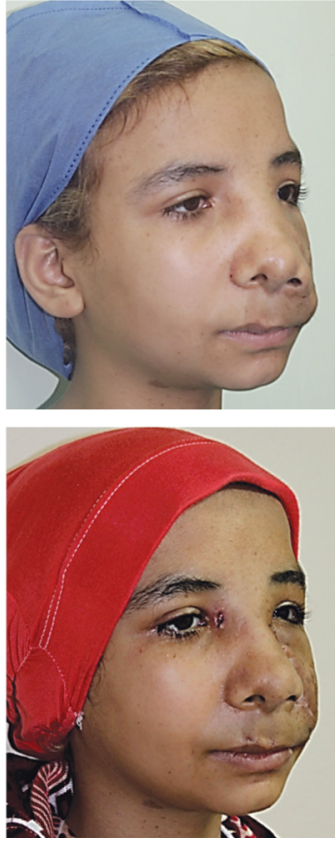

Fig. (11): Female patient 18 years old with neurofibromatosis affecting the midface with skeletal deformity in the form of maxillary hypertrophy. A single stage debulking of the tumor was and no skeletal maxilla osteotomies or shaving was done. The incisions used: at the scars of previous surgeries i.e. the nasolabial fold and side of the nose. She was operated three times in another center. Pre-operative photos upper row, post-operative photos lower row. 

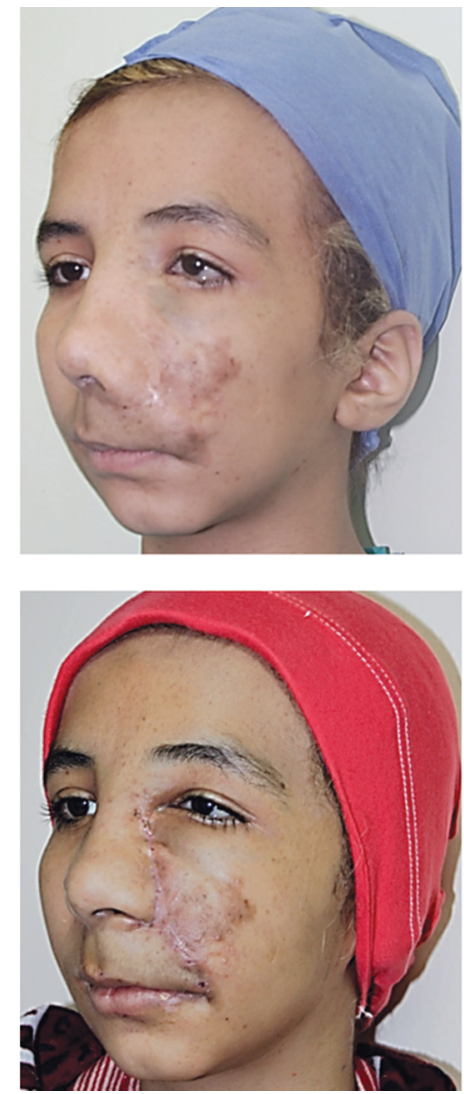

Fig. (12): Rest of the Pre-operative photos upper row, post-operative lower row.
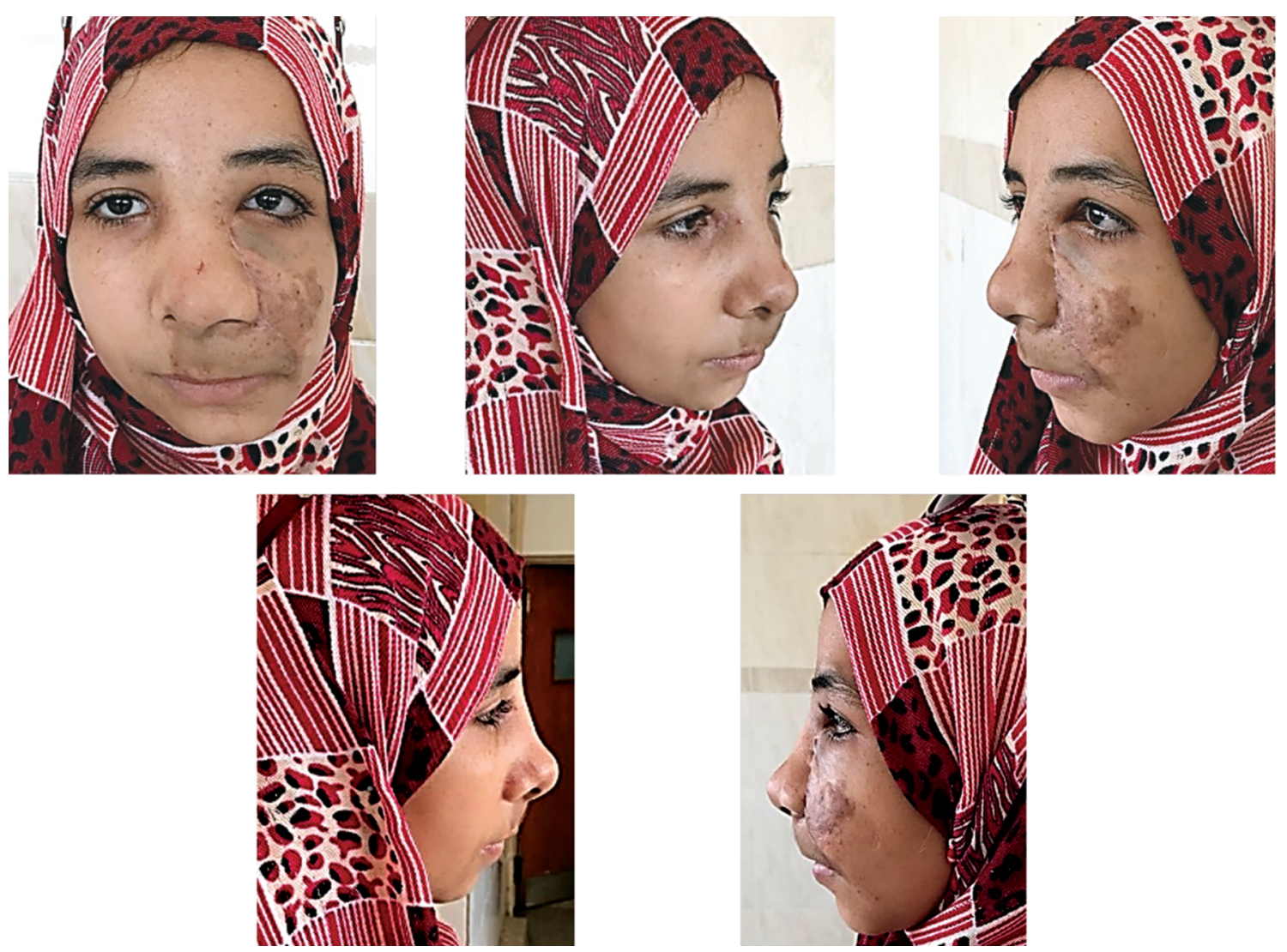

Fig. (13): Post-operative result after 12 month post-operative time. 

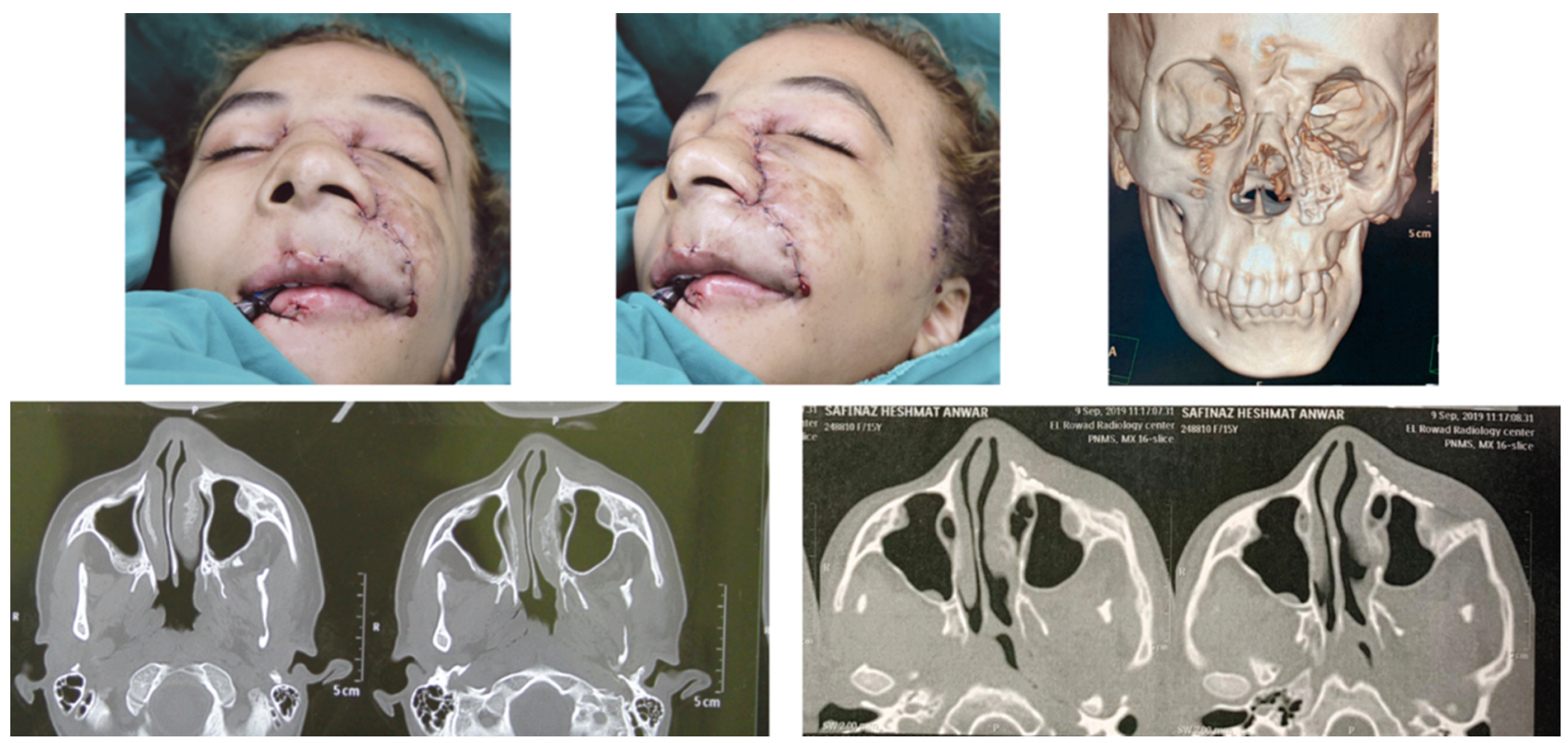

Fig (14): Intra operative photos showing the transnasal canthopexy, sagittal and 3D of CT scan showing the pre and postoperative shaving of the zygoma and using a titanium mesh to reconstruct the nasolabial grove.

\section{DISCUSSION}

Plexiform neurofibromatosis is considered the main cause of morbidity in the craniofacial region. Fortunately It is reported to be the least common type with less than $1 \%$ of NF1 patients [28]. Plexiform type present with unilateral rapid increase in size, tissue hypertrophy, hypertrichosis and hyperpigmentation with marked and functional and aesthetic disfigurement, [30] as seen in our patients (Figs. 1-13). Patients included in the study were categorized according to the site of lesion, as the management of craniofacial NF1 described in literature [16-21] is based on grading systems that categories lesions according to the site (orbitotemporal, [16,17], midface [18] and eyelid, [21]). The functional, aesthetic and psychological consequences of the long term, unpredictable, deformities are the main indications for surgery [12-14].

Timing of surgical intervention is debated in the literature for patients with extensive neurofibroma [17-19]. Neurofibromatosis tend to progress during growth sprouts and adolescence [31]. Radical excisions are delayed till stabilization or slow progression of the tumor, [18,19], and [44] which occur after 20 years $[\mathbf{1 8 , 3 3}]$. The functional and aesthetic disfigurement are the main key factors for surgical intervention in patients younger than 20 years $[\mathbf{3 0 , 3 3}$, aiming to reduce risks of injury of important structures as the trigeminal ad facial nerves [30]. This strategy was used in all our patient as seen in Case (1) and Case (2).
Cranioorbital NF1 is one of the most common type of head and neck neurofibromatosis. The earlier onset, the more aggressive and greater deformity. It is commonly present with increased volume of the bony orbit, deficient zygoma, malformed ipsilateral sinuses, enopthalmous or pulsating exophthalmos and sometimes herniated temporal lobe $[34,36]$.

It usually occur in young age less than 6 years with ocular findings as buphthalmos and Lisch nodules. Optic nerve gliomas are to be excluded in all patients [37]. Optic nerve compression, extraocular muscle affection, displacement of the globe all might lead to progressive impairment of vision and blindness [35]. Associated symptoms and signs are upper and/or lower eyelid swelling, eyelid ptosis due to the levetor muscle over stretch, brow asymmetry hypertrophy and ptosis, conjunctival and lacrimal affection, and canthal laxity up to disinsertion [18] (Figs. 1-3).

Frontal nerve affection might be iatrogenic or due to compression, stretch, and rarely from direct neural involvement. Skin changes include acneform texture with café au lait patch on the forehead, eyelid, temple or mid face [17-20]. Management of increased intraorbital volume might require osteotomies, bone or cartilage graft if the patient show marked enopthalmous or dystopia. Palpebral involvement is challenging to treat as recurrence and secondary surgery is common. Wedge resection, canthopexy, levator shortening and slings attached to the frontalis muscle. In all our cases with eye 
lid ptosis and canthal laxity, we did levator muscle reinsertion, wedge resection if needed and lateral canthoplasty using the proline mesh tailored in strips and attached to the boney orbit like the tongue in grove technique) (Figs. 4-7).

Midface involvement are most commonly associated with other types of head and neck neurofibromatosis. The tumor involve major sensory nerves (three branches of the trigeminal nerve) [55]. The severity and degree of affection is variable, bony canals widened and, distorting the structure of the nearby bony skeleton. V1 involvement result in extensive eyelid and periorbital manifestation. It can be associated with cranioorbital type or in isolation. V2 involvement result in asymmetry and proptosis of the ipsilateral eye. The maxillary bone hypertrophy cause dental abnormalities. V3 involvement result in mandibular region asymmetry with or without occlusal abnormalities [3].

Elephantiasis neurofibromatosis (Quasimodo disease) is a clinical variant which present with massive involvement of the soft tissue and boney skeleton, with significant facial deformities, and the chances or timing of presentation are unpredictable [40] (Figs. 8-10).

Patients with no prior surgical intervention can be treated with early radical surgery as this will produce the best long-term results. Incisions should be planned on the face to the respect of the facial subunits and soft tissue suspension of great importance to prevent residual facial ptosis [41]. This concept was adopted in the study in one patient case 1 (Figs. 1-3) showing very good result in 15 month follow-up time, using hidden incision over the preauricular temporal, hemi coronal and upper blepharoplasty incisions and suspension with proline mesh was done for the lateral canthus and the mid face. Treatment plane is individualized in such cases and surgical intervention is indicated before the tumor destroys the ligamentous adherence of the dermis to the underlying musculature, which might lead to functional and aesthetic disfigurement [41].

In patients with history of previous surgery they usually present with damage to important structures, inadequate excision and scarring. Subtotal resection is adopted with a staged approach, and facial subunits are preserved $[33,35]$. In patients with major deformity, hemifacial resection and reconstruction of the facial skeleton could be considered followed by microvascular soft-tissue reconstruction up to alloplastic hemifacial transplantation [42].
Clinical signs include medial canthus, upper and lower lip including the oral commissure, alar base displacement. It is common to have patients complaining of primary lesion of anatomic subunit while other areas are secondarily affected. It could affect the upper, lower or the whole nasal subunit. Pseudo-hypertelorism occur in patients with upper half involvement. Resection and simultaneous to correct the deformity and prevent post-surgical ectropion [43], and the same concept was used in all patients included in the study having pseudo hypertelorism (Figs. 11-14). Upper lip involvement results in horizontal, transverse and oral commissure excess tissue. Medial (lip) and lateral (nasolabial fold) wedge excisions are mandatory and oral commissure (modulus) suspension to the inferior orbital rim or body of zygoma is crucial to maintain long term results [43]. The proline mesh suspension technique was used in all our patients having lip and oral commissure involvement and it was fixed to the body or the arch of zygoma.

Hudge midface displacement need radical excision and reconstruction with tissue expanders [43], free flaps [44], and skin grafts with variable success. The study didn't include patients reconstructed with skin grafts, local or free flaps. However radical excision was done in such cases and tissue suspension using the proline mesh suspension technique in all our patients with mid face involvement and it was fixed to the body or the arch of zygoma.

The importance of tissue Suspension was revealed by the characteristics of NF-1 as the loss of skin elasticity, skin extensibility and tumor recurrence increases the tissue volume which will all act with the gravitational force adding to the deformity, making the long term results unpredictable $[\mathbf{4 5 , 4 6 ]}$. Durable tissue suspension can theoretically slow the tumor progression, as it minimize the effects of gravity on tumor tissue expansion [45]. The proline mesh was chosen for its durability and multiple strips with different vectors are used according to the facial submit suspended.

Previous studies used pre and post medical photography to evaluate their results. Xie et al., 2007 and Gabby et al., 2010 adopted surgical outcome rating scales. These rating scales assess are best used for static evaluation [46]. Craniofacial NF-1 is dynamic process that necessitate regular long term follow-up specially with the probability of new neurofibroma, recurrence, and malignant degeneration $[\mathbf{1 8 , 3 0 , 4 7 ]}$. In this study objective and subjective analysis was done, using Mimics software and Pre and post-operative photographs were 
examined by 3 plastic surgeons to analyze the clinical results. All the patients are still followingup in the outpatient clinic for the same reasons mentioned before.

Our patients according to the NAS score were rated average score $2.08( \pm 0.12)$, around categories II special in patients with both orbitotemporal and hemifacial lesions, while Lee et al., 2004 and Nagata 2006 showed patients with NAS score to fall between category II and III $[\mathbf{2 3 , 4 1 , 4 5 ]}$ symmetry improvement showed average $8.90 \%$ ( \pm ) $4.89 \%$, the mean percentage of improvement was lowest $(7.9 \%)$ among patients with both orbitotemporal and hemifacial lesions, which may require reassessment for the possibility of surgical revisions.

All patients underwent the postoperative CT, symmetry improvement was observed in all patients, with an average $8.90 \%$ ( \pm ) $4.89 \%$, and only patient number 8 was shown unsatisfactory result $-3.00 \%$, as shown in Table (4) and Diagram (5). Showing the relation between the pre and postoperative symmetry improvement in different site of lesions were calculated showing the mean percentage of improvement was highest $(9.51 \%)$ among patients with hemifacial lesions and lowest (7.9\%) among patients with both orbitotemporal and hemifacial lesions (Diagram 7).

\section{Conclusion:}

Using the proline mesh to suspend the tissue hand on hand with NF1 tumor excision is of utmost importance, showing reliable long term satisfactory aesthetic outcome especial in recurrent cases and with minimal and acceptable complication rate. Neurofibromatosis type 1 is dynamic process and Patients should be followed-up in the outpatient clinic for long term assessment, which could be used as a prospective data to compare the present study with the future results.

\section{Acknowledgments:}

I would like to thank the plastic and maxillofacial surgery department specially the residence and nursing staff for their preoperative, operative and postoperative care of the patients included in the study.

\section{REFERENCES}

1- Jett K. and Friedman J.M.: Clinical and genetic aspects of neurofibromatosis 1. Genet Med., 12: 1-11, 2010.

2- Todman D.: Warts and the kings of Parthia: An ancient representation of hereditary neurofibromatosis depicted in coins. J. Hist. Neurosci., 17 (2): 141-146, 2008.

3- Friedrich R.E., Giese M., Schmelzle R., Mautner V.F. and Scheuer H.A.: Jaw malformations plus displacement and numerical aberrations of teeth in neurofibromatosis type 1: A descriptive analysis of 48 patients based on panoramic radiographs and oral findings. J. Craniomaxillofac. Surg., 31 (1): 1-9, 2003.

4- Chrcanovic B.R., Gomez R.S. and Freire-Maia B.: Neurofibromatosis type 1 associated with bilateral central giant cell granuloma of the mandible. J. Craniomaxillofac. Surg., 39 (7): 538-543, 2011.

5- Friedrich R.E., Hagel C. and Scheurer H.A.: Orbital dysplasia and plexiform neurofibroma in NF1. J. Craniomaxillofac. Surg., 36: S152, 2008.

6- Apaydin A. and Chan T.: Oral manifestations of neurofibromatosis 1: A case report. J. Craniomaxillofac. Surg., 36: S221, 2008.

7- Koblin I. and Reil B.: Changes of the facial skeleton in cases of neurofibromatosis. J. Maxillofac. Surg., 3 (1): 23-27, 1975.

8- Krastinova-Lolov D. and Hamza F.: The surgical management of cranio-orbital neurofibromatosis. Ann. Plast. Surg., 36 (3): 263-269, 1996.

9- Jackson I.T.: Management of craniofacial neurofibromatosis. Facial Plast. Surg. Clin. North Am., 9 (1): 59-75, 2001.

10- van der Meulen J.: Orbital neurofibromatosis. Clin. Plast. Surg., 14 (1): 123-135, 1987.

11- Chou E-K., Chen K-T. and Tansipek B.: Palliative surgical treatment of the plexiform facialneurofibroma e a case report. J. Plast. Surg. Assoc. R.O.C., 14: 249-255, 2015.

12- Merker V.L., Bredella M.A., Cai W., et al.: Relationship between whole-body tumor burden, clinical phenotype, and quality of life in patients with neurofibromatosis. Am. J. Med. Genet A., 164A: 1431-1437, 2014.

13- Hirbe A.C. and Gutmann D.H.: Neurofibromatosis type 1: A multidisciplinary approach to care. Lancet Neurol., 13: 834-843, 2014.

14- Parsons C.M., Canter R.J. and Khatri VP.: Surgical management of neurofibromatosis. Surg. Oncol. Clin. N. Am., 18: 175-196, 2009.

15- Marchac D.: Intracranial enlargement of the orbital cavity and palpebral remodeling for orbitopalpebral neurofibromatosis. Plast. Reconstr. Surg., 73: 534-543, 1984.

16- Jackson I.T.: Neurofibromatosis of the skull base. Clin. Plast. Surg., 22: 513-530, 1995.

17- Jackson I.T., Carbonnel A., Potparic Z., et al.: Orbitotemporal neurofibromatosis: Classification and treatment. Plast. Reconstr. Surg., 92: 1-11, 1993.

18- Lee V., Ragge N.K. and Collin J.R.: Orbitotemporal neurofibromatosis. Clinical features and surgical management. Ophthalmology, 111: 382-388, 2004.

19- Marchac D. and Britto J.A.: Remodelling the upper eyelid in the management of orbitopalpebral neurofibromatosis. Br. J. Plast. Surg., 58: 944-956, 2005.

20- Erb M.H., Uzcategui N., See R.F. and Burnstine M.A.: Orbitotemporal neurofibromatosis: classification and treatment. Orbit., 26: 223-228, 2007. 
21- Singhal D., Chen Y.C., Tsai Y.J., et al.: Craniofacial neurofibromatosis: Treatment of the midface deformity. J. Craniomaxillofac. Surg., 42: 595-600, 2014.

22- Fattahi T.T.: An overview of facial aesthetic units. J. Oral Maxillofac. Surg., 61: 1207-1211, 2003.

23- Burget G.C. and Menick F.J.: The subunit principle in nasal reconstruction. Plast. Reconstr. Surg., 76: 239-247, 1985.

24- Shuxian Z., Wanhua Z. and Bingheng L.: 3D reconstruction of the structure of a residual limb for customising the design of a prosthetic socket. Med. Eng. Phys., 27: 67$74,2005$.

25- Liu Y., Gong Z., He L., et al.: Individual digital design and functional reconstruction of large mandibular defect with computer-aided design computer aided manufacture technique. Zhongguo Xiu Fu Chong Jian Wai Ke Za Zhi, 19: 803-806, 2005.

26- Li J., Zhang H., Yin P., et al.: A new measurement technique of thecharacteristics of nutrient artery canals in tibias using Materialise's Interactive Medical Image Control System Software. Biomed Res. Int., 2015: 171672, 2015.

27- Gabbay J.S., Yuan J.T., Andrews B.T., et al.: Fibrous dysplasia of the zygomaticomaxillary region: Outcomes of surgical intervention. Plast. Reconstr. Surg., 131: 13291338,2013

28- Singhal D., Chen Y.C., Chen Y.R., et al.: Soft tissue management of orbitotemporal neurofibromatosis. J. Craniofac. Surg., 24: 269-272, 2013.

29- Hivelin M., Wolkenstein P., Lepage C., et al.: Facial aesthetic unit remodeling procedure for neurofibromatosis type 1 hemifacial hypertrophy: report on 33 consecutive adult patients. Plast Reconstr Surg., 125: 1197-1207, 2010. Surg. Oncol. Clin. N. Am., 18: 175-196, 2009.

30- Hivelin M., Wolkenstein P., Lepage C., et al.: Facial aesthetic unit remodeling procedure for neurofibromatosis type 1 hemifacial hypertrophy: Report on 33 consecutive adult patients. Plast. Reconstr. Surg., 125: 1197-1207, 2010 .

31- Nguyen R., Ibrahim C., Friedrich R.E., et al.; Growth behavior of plexiform neurofibromas after surgery. Genet Med., 15: 691-697, 2013.

32- Altan-Yaycioglu R. and Hintschich C.: Clinical features and surgical management of orbitotemporal neurofibromatosis: A retrospective interventional case series. Orbit., 29: 232-238, 2010.

33- Nagata S.: A systematic multiple stage surgical approach for attainment of satisfactory and favourable surgical results in an extremely severe von Recklinghausen's disease, elephantiasis neurofibromatosa. J. Plast. Reconstr. Aesthet. Surg., 59: 662-674, 2006.

34- Bruwer A.J. and Kierland R.R.: Neurofibromatosis and congenital unilateral pulsating and nonpulsating exophthalmos. AMA Arch. Ophthalmol., 53: 2-12, 1955.

35- Hunt J.C. and Pugh D.G.: Skeletal lesions in neurofibromatosis. Radiology, 76: 1-20, 1961.

36- Havlik R.J. and Boaz J.: Cranio-orbital-temporal neurofibromatosis: Are we treating the whole problem? J. Craniofac. Surg., 9: 529-535, 1998.

37- Hersh J.H.: Health supervision for children with neurofibromatosis. Pediatrics, 121: 633-642, 2008.

38- Snyder B.J., Hanieh A., Trott J.A., et al.: Transcranial correction of orbital neurofibromatosis. Plast. Reconstr. Surg., 102: 633-642, 1998.

39- Greig A.V., Kirkpatrick N.A., Joshi N., et al.: Giant hemifacial plexiform neurofibroma arising from trigeminal ganglion. J. Craniofac. Surg., 20: 833-836, 2009.

40- Chen Y.R., Chen K.T. and Noordhoff M.S.: Facial elephantiasis neurofibromatosa: Excision and skin graft. Ann. Plast. Surg., 23: 547-551, 1989.

41- Phillips J.H., Gruss J.S., Wells M.D., et al.: Periosteal suspension of the lower eyelid and cheek following subciliary exposure of facial fractures. Plast. Reconstr. Surg., 88: 145-148, 1991.

42- Gomez-Cia T., Sicilia-Castro D., Infante-Cossio P., et al.: Second human facial allotransplantation to restore a severe defect following radical resection of bilateral massive plexiform neurofibromas. Plast. Reconstr. Surg., 127: 995-996, 2011.

43- Singhal D., Chen Y.C., Seselgyte R., Chen P.K. and Chen Y.R.: Craniofacial neurofibromatosis and tissue expansion: Long-term results. J. Plast. Reconstr. Aesthet. Surg., 65 (7): 956-959, 2012.

44- Singhal D., Chen Y.C., Fanzio P.M., Lin C.H., Chuang D.C., Chen Y.R., et al.: Role of free flaps in the management of craniofacial neurofibromatosis: Soft tissue coverage and attempted facial reanimation. J. Oral Maxillofac. Surg., 70 (12): 2916-2922, 2012.

45- Acartürk T.O., Yigenoglu B. and Pekedis O.: Excision and "transcutaneous" lift in patients with neurofibromatosis of the fronto-temporo-orbital and auricular regions. J. Craniofac. Surg., 20: 771-774, 2009.

46- Xie Y., Li Q., Zheng D., et al.: Correction of hemifacial atrophy with autologous fat transplantation. Ann. Plast. Surg., 59: 645-653, 2007.

47- Chaudhry I.A., Morales J., Shamsi F.A., et al.: Orbitofacial neurofibromatosis: Clinical characteristics and treatment outcome. Eye (Lond), 26: 583-592, 2012. 